\title{
The innovation research on the extraction technology of Ganoderma lucidum
}

\section{Chen Liang* \\ Fuzhou East Star Biotechnology Co. Ltd., Fuzhou, China \\ *Correspondence: donxin1988@163.com}

China is the birthplace of the Chinese Medicine. Ganoderma lucidum as a traditional Chinese treasure with Millenium history of medicinal herbs, its medical and health care functions have come to be known to the general public. With the development of technology, G. lucidum health food ceaseless emerges in large numbers. But G. lucidum health food differs in efficacy, component, and content; health care effect is not the same, for this reason, it is closely related to the extraction technology of G. lucidum (Lin, 2007). Extract of G. lucidum extract objective is to maximize the active ingredient within the material, the extraction process in the heating mode, the relative motion of the solid-liquid twophase state, are easy to lead to different extraction speed and effectiveness.

For the G. lucidum health food, choosing the appropriate extraction technology and equipments is the key step to the production. In order to make this process successfully completed, for equipment, the optimization of extraction methods and mode of heating that affect the extraction effect most.

This G. lucidum extraction device, which consists of heat extraction device and the installation, the green part is heating medium circulation line, and the red part is extraction circular route. The map is introduced base on oil as the heating medium, water as solvent. The device constituted by six key groups. Its work program is:

Extract gets through filters to reach the tubular heat exchanger tube by the effect of gas-liquid mixing pump, and the heat transfer oil driven to reach out at hightemperature under the leading by hot oil circulation pump, the hot and cold liquids in a tubular complete heat exchange in heat exchanger, the heating of the extract re-pump back to the extraction tank, the process is cyclical, exist in the whole extraction process (Wang et al., 2000).

\section{THE TECHNICAL CHARACTERISTICS ON INNOVATIVE TECHNOLOGY OF GANODERMA LUCIDUM EXTRACT HEATING TECHNICAL AND INNOVATION The application of improving heating method} Traditional extraction methods use more heating jacket, it sets jacket in the extraction tank wall, which leads to heat conduction through the partitions to complete the process of heat transfer. Schematic can be seen in the outer layer of the insulating layer, middle layer is heated, the internal is the extract, this time, the heat is always around the material, transfer from the outside to inside slowly, the temperature of the bottom, middle material is too low, the effect of heat transfer is limited, not be extracted completely (Liu and Zhao, 2002).

Innovative technology of G. lucidum extraction using tubular heat exchanger, the device structure is different from the traditional heating method.

It can be seen on the schematic of the device, it is mainly made of the tubular heat exchanger, heat generating devices, hightemperature oil circulating pump, filtration system, and the corresponding piping components. The outside of tubular heat exchanger is cylindrical, with a number of controls inside, the fluid inside pipe is extract fluid (yellow); outside fluid is heat (red). Hot and cold fluids flow respectively in the opposite direction, relies on their high-temperature circulation pump, so the heat can be exchanged. The dynamic cyclic heating only heat flows through the shell, so the heat transfer will be more efficient (Lixi et al., 2008).

\section{The application of improving heat to diversity}

Traditional extraction techniques heating device is heat-conducting oil or steam boiler heat generated with a single heat source. The extraction of this item selected carbon steel as the material within the bundle of heat exchanger, the shell and road of tube have been handled by pressure-proof, so it could work normal at high-temperature and highpressure. The use of heat generating device can be HTF or steam generator (Table 1).

\section{TECHNICAL AND INNOVATIVE EXTRACTION METHODS \\ The application of forced circulation and dynamic extraction}

The traditional methods use more on maceration extraction method, it is static extraction, materials, and solvents are in a relatively quiescent state, the material heated area is limited and uneven, solvent flow is not strong, they affected the material leaching component diffusion.

In the extraction process of Chinese herbal medicines, edible and medicinal fungi, if the liquid is always maintained good liquidity, resulting in a good concentration difference, it will greatly accelerate the leaching of the active ingredient from extract. So the new technology to extract $G$. lucidum extract using cyclic method, from static to dynamic forced circulation extraction (Table 1).

Leachate get through the high-temperature-proof gas-liquid mixture circulating pump to the bottom of the tank, filtered, heated, and then pump back leaching to the top of tank, then sprayed, and washed by high-pressure nozzle. Force circular operation until the extraction completed. It makes full access to the material to be extracted with solvents, and complete (Table 1).

\section{The application of improving the methods for putting in and getting out materials}

Traditional extraction techniques put in materials from the top, and take out the waste from the bottom, mostly are coneshaped structure. In the actual production, due to the small size of the device's bottom, the material can easily plugged here, difficult to be flushed off (Table 1).

This extraction technology device to extract the structure using the straightshaped structure, two-cylinder hydraulic 
Table 1 | Comparison of extraction.

\begin{tabular}{|c|c|c|c|}
\hline Extraction & Heating & Extraction method & Technical features \\
\hline $\begin{array}{l}\text { The traditional extraction } \\
\text { technology }\end{array}$ & Jacketed type & Immersion type & $\begin{array}{l}\text { Heat transfer surface is limited by the wall of extracting tank, the } \\
\text { coefficient of heat transfer is small, the heat source is always around with } \\
\text { the material, heat is difficult to transfer to inside, it is easy to form the heating } \\
\text { dead ends, and make the temperature of material at the bottom and middle } \\
\text { too low, the effect of heat transfer is limited, and easy to cause the extraction } \\
\text { incomplete } \\
\text { Material and solvent is in a relatively static state, heated area of material is } \\
\text { limited and uneven, solvent mobility strong, affect efficiency is not high }\end{array}$ \\
\hline $\begin{array}{l}\text { The innovation extraction } \\
\text { technology of } \\
\text { Ganoderma lucidum }\end{array}$ & Tubular type & Circulation type & $\begin{array}{l}\text { Tubular type heat in the external, heat transfer surface is not limited by the } \\
\text { wall of extracting tank, liquid feeding pipes are arranged in a honeycomb } \\
\text { shape, heat transfer area increased, without the heating dead ends, the heat } \\
\text { exchange efficiency is improved, the heating time is shorten, and extraction is } \\
\text { completely } \\
\text { Leaching solution is pump out from the bottom of the tank by high- } \\
\text { temperature gas-liquid circulating pump, filtering, heating, then the leaching } \\
\text { solution is pumped back to the upper part of the tank body, with the } \\
\text { high-pressure nozzle jet injector materials, this forced circulation until the } \\
\text { extraction task complete. It makes extraction completely with the material } \\
\text { and solvent full contact. }\end{array}$ \\
\hline
\end{tabular}

drive top open structure, it will place materials in the transparent stainless steel basket, and then taken to the extract tank by mechanical, all the process for transporting the materials are finished by mechanism, thus it avoids the waste plugged at bottom (Table 1).

\section{THE ACHIEVEMENTS OF INNOVATION RESEARCH ON THE EXTRACTION TECHNOLOGY OF GANODERMA LUCIDUM}

Innovation research on G. lucidum extract technology, the result just transferred in East Star Biotechnology Co. Ltd., Fuzhou, China. The economic benefits of its successful application can be as follows:

1. Reduce energy consumption

To extracting $100 \mathrm{~kg}$ G. lucidum fine powder as an example, the traditional technology requires power $20,000 \mathrm{~kW}$, this technology requires only $7500 \mathrm{~kW}$. Energy consumption reduces about $62.5 \%$.

2. Improve the extraction yield

To extracting $100 \mathrm{~kg} \mathrm{G}$. lucidum fine powder as an example, the traditional technology need to consume about $2000 \mathrm{~kg}$ G. lucidum fruit body raw material, this technology consume about $1250 \mathrm{~kg} G$. lucidum fruit body raw material, Compared with the traditional technology, the extraction yield of the material can improve by about $37.5 \%$.

3. Shorten the extraction time

An installed capacity of $200 \mathrm{~kW}$ as an example, the traditional technology needs $10 \mathrm{~h}$, this technology only need $6 \mathrm{~h}$, the desired time can be reduced by about $40 \%$. 4. Solvent saving

An installed capacity of $200 \mathrm{~kW}$ as an example, the traditional technology needs the ratio of the material and liquid is $1: 15$; this technology is $1: 10$. Compared with the traditional technology, solution volume reduces about $33 \%$.

These figures show that innovative technology of G. lucidum extract has obvious economic and social benefits compare to the traditional extraction techniques.

\section{DISCUSSION AND CONCLUSION}

The extraction and processing of G. lucidum is the key technology to the development and production of health product, it directly influences the effective composition content of G. lucidum products. Innovative study on the extraction technology of G. lucidum and its application in production can effective make up for the shortage of the traditional extraction in the extraction yield and unit consumption, and improve production efficiency of the enterprise, reduces energy consumption.

\section{REFERENCES}

Lin, Z. M. (2007). Modern research of Ganoderma lucidum, 113-118.

Liu, H., and Zhao, C. J. (2002). Several Chinese herbal medicines to strengthen the multi-function extractor extraction method. J. Chin. Med. Mat. 25, 919-921.

Lixi, X. S. D., Feng, J. A., and Huang, Y. J. (2008). Dynamic countercurrent extraction technology in traditional Chinese medicine extraction. J. Pract. Chin. Med. 191, 806-808.

Wang, Z., Peng, W., and Li, D. J. (2000). Large tubular heat exchanger manufacturing technology. Large Scale Nitrogen Fertilizer Ind. 23, 231-234.

Received: 18 January 2012; accepted: 11 April 2012; published online: 18 June 2012.

Citation: Liang C (2012) The innovation research on the extraction technology of Ganoderma lucidum. Front. Pharmacol. 3:79. doi: 10.3389/fphar.2012.00079

This articlewassubmitted to Frontiers in Ethnopharmacology, a specialty of Frontiers in Pharmacology.

Copyright (c) 2012 Liang. This is an open-access article distributed under the terms of the Creative Commons Attribution Non Commercial License, which permits non-commercial use, distribution, and reproduction in other forums, provided the original authors and source are credited. 